\section{Stress factors during cattle slaughter}

Chiara Disanto, ${ }^{1}$ Giuseppe Celano, ${ }^{1}$ Michele Varvara, ${ }^{2}$ Nunziana Fusiello, ${ }^{2}$ Armida Fransvea, ${ }^{1}$ Giancarlo Bozzo, ${ }^{2}$ Gaetano Vitale Celano ${ }^{2}$

1Med \& Food C.Q.S. Srl., Valenzano (BA); 'Dipartimento di Medicina Veterinaria, Università degli Studi di Bari Aldo Moro, Valenzano (BA), Italy

\section{Abstract}

Monitoring animal welfare at a slaughterhouse is somehow different from the situation on the farm. The throughput numbers can be very high, and there is no possibility to know the individual history, background or habits of each animal. The animals are unfamiliar to the staff and viceversa. Furthermore, most animals will be unknown to each other even if they may be delivered in groups or batches, and it is not rare to see mixing of completely unfamiliar animals. The slaughter plants' environment is of course completely unknown to the animals, with large areas not always designed to minimize noise or visual distraction for animals. Sub-optimal handling of animals can unfortunately be seen at many slaughterhouses, where animals are coerced roughly, using sticks or prods and loud voices, forcing the animals to move fast in the desired direction. Vets need to be aware of these factors because they can cause excessive prodding for animals, which may become balking, excited and stressed. A survey of 10 italian slaughter plants revealed that: 5 plants had slick floors that would cause animals to slip and fall, 9 plants had high pitched motor noise or hissing air that made animals balking; air drafts blowing down the chutes, which will often impede animal movement, were a problem in 9 of the observed plants. Simple modifications of lighting and elimination of air drafts and hissing will often greatly improve animal movement.

\section{Introduction}

At the time of their arrival at the slaughterhouse, cattle find themselves in a totally unknown universe where they will be handled by staff whose primary objective is often to maintain an adequate speed of slaughter, also at the expense of a proper management of animals. Since their departure from the farm, cattle live a stress condition caused by the new environment and by the contact with other animals. This situation, however, is inevitable. According to Grandin (1981), animals do nt react similarly to the stress; some cattle are better adapted to the new environment and these are less restless, while others have a marked state of excitement. Scientific studies have shown that these behaviors are influenced by a series of stress factors such as individual sensitivity, breed characteristics, age and sex of the animals. Italian Friesian Cattle and Brown Swiss cattle are less sensitive to stressful events during the slaughter than young cattle of meat breed (Limousine, Charolais, Blue Belga, etc.) because they have already had contact with man for many operations such as milking, artificial insemination and veterinary care. According to Terlouw et al. (2007), stress condition during the slaughter could have different origin: physical (fatigue, lack of food or water, poor temperature or poor air quality, falls) and psychological (for social disorders such as separations, mixtures of unknown animals, fear of an environment unfamiliar or fear to the presence of man). The final quality of the meat is influenced by stress suffered by cattle in pre-slaughter. Another important stress factor is the presence of loud noises during slaughter operations. The sound level of squealing is correlated to blood lactate concentration and creatine kinase activity in cattle (Calkins et al., 1980; Cockrum and Corley, 1991). Practical experience and observations by Grandin in more than 200 beef and pork slaughter plants in the United States, Canada, Mexico, Europe, Australia, and New Zealand indicate that careful, quiet handling in the stunning chute will reduce PSE; dark, firm, and dry meat (Grandin, 1981, 2003).

Structures that do not comply are important stress factors for the animals. Livestock handling should be as short as possible, designed and constructed so as to allow the animals to move freely in the appropriate direction, according to their behavioral characteristics and without distraction. Furthermore, any element of disturbance such as hanging clothes, flashing lights, changes in lighting conditions, moving objects (fan blades) must be eliminated. The floor of slaughterhouse must be realized and maintained so as to minimize the risk of animals slipping, falling or injuring limbs. If these criteria are not respected, the slaughter line could be slowed. All this, could induce also the staff responsible for the handling of animals to adopt improper attitudes. In these situations the use of tools to stimulate the animals (electric prod) by operators will be recurring. A bovine's heart rate will increase with each successive application of an electric prod.

These cattle will have a greater probability of providing carcasses with lesions (bruising, petechial hemorrhages, etc.) for the excessive
Correspondence: Gaetano Vitale Celano, Dipartimento di Medicina Veterinaria, Università degli Studi di Bari Aldo Moro, strada provinciale per Casamassima km 3, 70010 Valenzano (BA), Italy.

Tel. +39.080 .5443850 - Fax: +39.080 .5443855 .

E-mail: gaetanovitale.celano@uniba.it

Key words: Stress factors, Cattle slaughter, Animal welfare.

Funding: the present research has been funded by the PSR 2007-2013 ASSE I Pif Project.

Received for publication: 12 May 2013

Revision received: 26 January 2014.

Accepted for publication: 28 February 2014.

This work is licensed under a Creative Commons Attribution 3.0 License (by-nc 3.0).

(C) Copyright C. Disanto et al., 2014

Licensee PAGEPress, Italy

Italian Journal of Food Safety 2014; 3:1682

doi:10.4081/ijfs.2014.1682

use of the electric prod and for falls, slips and trauma against the corridor bulkheads that are frequent especially if the animal does not have enough space for progression and for the movement. The refuse to move by cattle and the attempts to mounts between subjects could also be caused by a lack of employee training or poor supervision of employees (Van Putten and Elshof, 1978). The new legislation on animal welfare during slaughter, Reg. 1099/2009/EC (European Commission, 2009), applicable since 1 January 2013 and valid in all EU countries, contemplate a training plan for the employees of slaughterhouse. The lack of training of employees and consequently the lack of knowledge of the animal ethology (flight zone) leads to a bad interaction between man and animal. The knowledge of flight zone allow physiological movement of the animal, without the use of gory means (such as sticks or the same electric prod) that are important stress factors. According to Lemoine et al. (2006), the devices that allow to minimize the stress in the pre-slaughter are: entry of cattle in stunning box only when the operator is in position ready to perform stunning, adequate illumination of stunning box; avoid the vision of animals already slaughtered through the use of tents between the stunning box and the forcing pen; clean regularly the stunning box to eliminate the presence of blood; stunning box and forcing pen with nonslip floor (rubber floor mats); avoid multiple entry of animals into the stunning box; adapt the height of the walls of the stunning box to the size of the animal. 


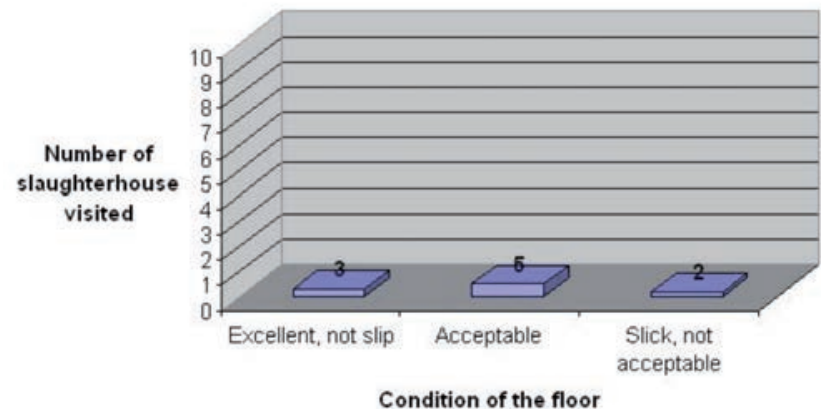

Figure 1. Condition of the floor in 10 slaughterhouses visited.

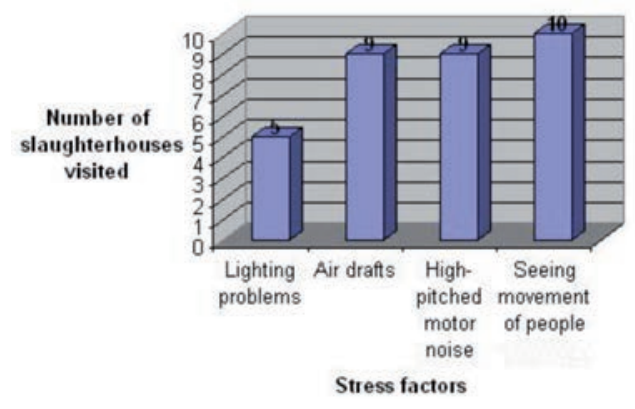

Figure 2. Stress factors during slaughter cattle in 10 slaughterhouses of Bari Province, Southern Italy.

\section{Materials and Methods}

The purpose of this research was to evaluate the welfare during slaughter cattle, monitoring 4 factors that could cause significant stress in the phases preceding stunning. The variables considered are the following: structural characteristics of the plants (ramps and forcing pen), environmental factors (type of ventilation and lighting, presence of noise and/or air currents, type of flooring and temperament of the animals. These factors were evaluated by a series of visits carried out weekly from April 2012 to September 2012, at 10 slaughtering plants of cattle in Puglia region.

\section{Results}

In an high percentage of plants the presence of unsuitable floor (5 plants, 50\%) was found (Figure 1). These floors, greatly worn, were observed mainly near the stunning box or in the areas of greatest passage of animals. In these areas cattle had difficulty moving because of irregularities in the floor. Mistakes in the design of forcing pen (9 plants) determined the presence of air drafts that have often determined the recoiling of the animals, with the consequent use of the electric prod by operators. In a slaughterhouse has been observed that excessive lighting in association with the presence of air drafts, blocking cattle at the entrance of the stunning box (Figure 2). During the visits the presence of staff poorly formed, unmotivated or uncontrolled has often been observed. In almost all the plants visited a great number of subjects was observed in the forcing pen, in order to speed the slaughter. All this can may cause great stress in cattle.

\section{Discussion and Conclusions}

Monitoring animal welfare at a slaughterhouse is somewhat different from the situation on the farm. The new legislation Reg. EC 1099/2009 (European Commission, 2009) introduces provisions concerning: layout, construction and equipment of slaughterhouses; handling and stunning operations at slaughterhouses; responsibility of the operator. From the results of this work structural weaknesses of slaughterhouses have emerged. They are related to an incorrect design, which probably has not seen the involvement of the veterinary who has considerable knowledge of the animal welfare. The study showed that mistakes in behaviour of the slaughter staff are due to a lack of specific training in welfare and to a poor supervision of employees. Hereafter in order to ensure a major supervision of employees, video surveillance systems could be provided in the slaughterhouses. These systems do not represent elements of disorder for both the animals and the operators and they could provide information about the phases before slaughter. In addition, the periodic compilation of ministerial checklists by the official veterinarian of the plant could highlight some of the issues present in slaughterhouses, such as the presence of slippery floors, excessive noise, errors ventilation or lighting, for which the maintenance and correction by the feed and food operators is prescribed.

\section{References}

Calkins CR, Davis GW, Cole AB, Hutsell DA, 1980. Incidence of blood-splashed hams from hogs subjected to certain antemortem handling methods. J Anim Sci 50:15.

Cockrum MS, Corley KTT, 1991. Effect of preslaughter handling on the behavior and blood composition of beef cattle. Vet $\mathrm{J}$ 147:444-54.

European Commission, 2009. Commission Decision of 24 September 2009 concerning certain the protection of animals at the time of killing, 2009/1099/EC. In: Official Journal, L 303, 18/11/2009, pp 1-30.

Grandin T, 1981. Bruises on southwestern feedlot cattle. J Anim Sci 53:213.

Grandin T, 2003. Transferring results of behavioural research to industry to improve animal welfare on the farm, ranch and the slaughter plant. Appl Anim Behav Sci 81:215-28.

Lemoine E, Frencia JP, Brule A, 2006. Document pédagogique de préconisations sur la manipulation, la contention et l'étourdissement des bovins et ovins en abattoirs. ADIV, Institut de l'Elevage Interbev. Publ, Paris, France.

Terlouw E, Arnould C, Auperin B, Berri C, Le Bihan-Duval E, Lefevre F, Lensink J, Mounier L, 2007. Impact des conditions de pré-abattage sur les stress et le bien-être des animaux d'élevage. INRA Prod Anim 20:93-100.

Van Putten G, Elshof WJ, 1978. Observations on the effect of transport on the well-being and lean quality of pigs. Anim Regulat Stud 1:247-71. 